\title{
Comparative Analysis of Proteoglycans Synthesized by Chick Corneal Stromal Cells in Cell Culture and Organ Culture
}

\author{
Ikuko TAKAHAShI, ${ }^{a}$ Susumu SAShima, ${ }^{b}$ and Kiyoshi NAKAZAWA ${ }^{*, b}$ \\ RI Center ${ }^{a}$ and Section of Radiochemistry, ${ }^{b}$ Faculty of Pharmacy, Meijo University, 150 Yagotoyama, Tempaku-ku, Nagoya \\ 468-8503, Japan. Received August 2, 2000; accepted September 14, 2000
}

\begin{abstract}
Proteoglycans (PGs) synthesized by chick corneal stromal cells in cell culture and organ culture were metabolically radiolabelled with $\left[{ }^{35} \mathrm{~S}\right]$ sulfate (for glycosaminoglycans) and $\left[{ }^{3} \mathrm{H}\right]$ leucine (for core proteins). Media, cell extracts and organ extracts from cultures were chromatographed on DEAE-Sephacel columns and separated into three fractions: the pass-through fraction (Fraction 1: nonsulfated PGs, hardly sulfated PGs, or glycoproteins with some oligosaccharides), the fraction eluted with a low salt concentration (Fraction 2: undersulfated PGs), and the fraction eluted with a high salt concentration (Fraction 3: highly sulfated PGs). The PG compositions of each fraction of cell culture and organ culture were then compared. While the proportions of highly sulfated KSPG in Fractions 3 of medium and cell extract of cell culture were both very low compared with those of medium and organ extract of organ culture, respectively, the proportions of highly sulfated CS/DS PG in Fractions 3 of those of cell culture were higher than those of organ culture. On the other hand, the proportions in the ${ }^{35} \mathrm{~S}$ activities of nonsulfated or undersulfated KSPG in Fractions 1 and 2 of medium and cell extract of cell culture were comparable to those of organ culture. Furthermore, the proportions of core proteins of undersulfated KSPG in Fractions 2 were higher in cell culture than in organ culture. These results show that, when the cells are cell-cultured, the degree of sulfation of KS chains decreases markedly, but the syntheses of the glycosaminoglycan backbone and core protein are maintained.
\end{abstract}

Key words undersulfated proteoglycan; corneal stromal cell; keratan sulfate; chondroitin sulfate/dermatan sulfate

Two families of small proteoglycans (PGs) are present in the adult chicken corneal stroma: one with chondroitin sulfate/dermatan sulfate (CS/DS) side chains, which is identical to decorin ${ }^{1)}$; and the other with keratan sulfate (KS) side chains, which consists of three PGs containing the genetically distinct core proteins, lumican, ${ }^{2}$ keratocan, ${ }^{3)}$ and osteoglycin/mimecan. ${ }^{4)}$ These PGs help maintain the regular arrangement of collagen fibrils within the corneal stroma ${ }^{5-7)}$ and play an important role in corneal transparency. ${ }^{8)}$

In normal corneal stroma of many mammals and birds, the two families of PGs are present in almost the same amounts. ${ }^{9-14)}$ But the accumulation and biosynthesis of the two families of PGs in corneal stroma readily change with changes in conditions in vivo and in vitro. Especially, when corneal stromal cells were cultured on a plastic dish in vitro, the expression pattern of PG changed markedly ${ }^{15-20)}$ : KS biosynthesis mostly ceased, the proportions of CS/DS and heparan sulfate biosyntheses increased, and hyaluronic acid biosynthesis began. In contrast to these reports, Funderburgh et $a{ }^{21)}$ reported that KSPG decreased moderately in bovine corneal keratocyte cultures and constituted $15 \%$ of the proteoglycan metabolically labeled with $\left.{ }^{35} \mathrm{~S}\right]$ sulfate in the culture medium, and that KSPG made in vitro differs from that found in vivo in the length and sulfation of its KS chains. Schrecengost et $a l_{.}{ }^{22)}$ also reported from Western blotting of PG synthesized in chick corneal fibroblast culture that the precursor protein was converted to a glycoprotein with large oligosaccharides (probably poly- $N$-acetyllactosamine) and not to a proteoglycan in cell culture: the sulfation enzymes for KS may be absent in cultured corneal fibroblasts, although the poly- $N$-acetyllactosamine chain is produced there. Furthermore, Beales et al. ${ }^{23)}$ reported that bovine keratocytes cultured in serum-free medium synthesized $47 \%$ of the total glycosaminoglycan as KS, whereas the cells in medium containing 10\% FBS synthesized only $9 \%$ KS.
To resolve this confusion, in this study we analyzed PGs synthesized in cultures of chick corneal stromacytes and of corneal stromal tissues using glycosaminoglycan-degradative enzymes and antibodies against core proteins of KSPG and CS/DS PG, and examined the differences in PG compositions between the cell and organ cultures. Many previous papers show that the expression pattern of PGs in organ culture is similar to that in vivo. Considering that the PG biosynthesis in organ culture reflects that in vivo, we compared the composition of PG in cell culture with that in organ culture. We found that the proportion of highly sulfated KS was markedly decreased in the cell culture, while the proportion of the undersulfated KS was higher in the cell culture than in the organ culture. We also found that the considerable amounts of undersulfated PGs (KSPG and CS/DS PG) were secreted into the medium as final products in both cell culture and organ culture.

\section{MATERIALS AND METHODS}

Materials White Leghorn male chicks ( $2 \mathrm{~d}$ old) were purchased from Hattori Youkei-en, Nagoya. Chondroitinase ABC (Proteus vulgaris), Keratanase (Pseudomonas sp.), and endo- $\beta$-galactosidase (Escherichia freundii) were purchased from Seikagaku Corp., Tokyo. DEAE-Sephacel, CNBr-activated Sepharose 4B, High Trap Q, PD-10, Superose 6, Protein A-Sepharose, and E-Z-SEP (antibody purification kit) were purchased from Amersham Pharmacia Biotech, Tokyo. Ham's F-12 medium was purchased from Nissui Seiyaku, Tokyo. Fetal bovine serum (FBS), streptomycin sulfate, and penicillin $\mathrm{G}$ were purchased from Gibco BRL, U.S.A. Collagenase (Clostridium hystolyticum) was purchased from Wako Pure Chemical Ind., Osaka. L-[4,5-3H(N)]-Leucine and $\left[{ }^{35} \mathrm{~S}\right]$ sulfate (sodium salt) were purchased from NEN Life Science Products, U.S.A. 
Organ Culture, Cell Culture, and Labelling with Radioactive Precursors Organ culture of corneal stromas was done as reported previously. ${ }^{24)}$ Briefly, corneas were dissected from 24 male chickens $2 \mathrm{~d}$ after hatching. Corneal stromas were taken from the corneas by scraping off the epithelial and endothelial layers after their treatment with $0.1 \%$ EDTA. The stromal explants (16 per culture dish) were placed in $1 \mathrm{ml}$ of Ham's F-12 medium containing $3.7 \mathrm{MBq}$ of $\left[{ }^{3} \mathrm{H}\right]$ leucine and $11.1 \mathrm{MBq}$ of $\left[{ }^{35} \mathrm{~S}\right]$ sulfate and radiolabelled at $37^{\circ} \mathrm{C}$ for $5 \mathrm{~h}$ in a $\mathrm{CO}_{2}$-incubator. After radiolabelling, the medium was removed from the culture. The medium fraction, to which solid guanidine chloride was added to make about $4 \mathrm{M}$, was applied to a PD-10 column to remove unincorporated radioactive precursors as reported previously. ${ }^{24)}$ The cultured explants were extracted with $4 \mathrm{M}$ guanidine chloride solution containing $0.2 \mathrm{M} \mathrm{NaCl}, 10 \mathrm{~mm}$ EDTA, 6-aminohexanoic acid (AHA), $10 \mathrm{~mm} N$-ethylmaleimide (NEM), and $0.5 \%$ 3-[(3-cholamidopropyl)-dimethylammonio]-1-propane sulfonate (CHAPS) in $0.5 \mathrm{M}$ Tris- $\mathrm{HCl}, \mathrm{pH} 7.5$ as reported previously. ${ }^{24)}$

The cell culture of the stromal cells was done as reported previously. ${ }^{25}$ The corneal stromas were taken from 114 chicken eyeballs as described above, minced, and digested with $0.25 \%$ of collagenase in phosphate-buffered saline, $\mathrm{pH}$ $7.2\left(8.1 \mathrm{~mm} \mathrm{Na} \mathrm{HPO}_{4}, 0.14 \mathrm{M} \mathrm{NaCl}, 1.47 \mathrm{~mm} \mathrm{KH}_{2} \mathrm{PO}_{4}, 2.7\right.$ $\mathrm{mm} \mathrm{KCl}, 1 \times 10^{5} \mathrm{U}$ penicillin $\mathrm{G}$, and $0.1 \mathrm{~g}$ streptomycin sulfate in $1000 \mathrm{ml}$ ). The resultant cell suspension was divided into three parts, each of which was placed in $3 \mathrm{ml}$ of Ham's F-12/10\% FBS/100 U penicillin G on a culture dish $(2.16 \times$ $10^{6}$ cells/dish). The cells were cultured in $3 \mathrm{ml}$ of the medium in a $\mathrm{CO}_{2}$-incubator $\left(95 \%\right.$ air- $\left.-5 \% \mathrm{CO}_{2}\right)$ at $37^{\circ} \mathrm{C}$ for $8 \mathrm{~d}$. The medium was replaced daily. On the 9 th day, the medium was removed, and $1 \mathrm{ml}$ of the medium containing $11.1 \mathrm{MBq}$ of $\left[{ }^{35} \mathrm{~S}\right]$ sulfate and $3.7 \mathrm{MBq}$ of $\left[{ }^{3} \mathrm{H}\right]$ leucine was added to each dish. The cultures were radiolabelled in a $\mathrm{CO}_{2}$-incubator at $37^{\circ} \mathrm{C}$ for $5 \mathrm{~h}$. After radiolabelling, the medium was removed from the culture. As described above, solid guanidine chloride was added to the medium fraction, which was then applied to a PD-10 column to remove unincorporated radioactive precursors. The cell layer on the dish was extracted with $4 \mathrm{~m}$ guanidine chloride/protease inhibitors as described above. $^{20)}$

DEAE-Sephacel Column Chromatography The medium and stroma extract from organ culture (hereafter referred to as $\mathrm{OM}$ and $\mathrm{OE}$, respectively) and the medium and cell extract from cell culture (hereafter referred to as $\mathrm{CM}$ and $\mathrm{CE}$, respectively) were dialyzed against $7 \mathrm{M}$ urea in $50 \mathrm{~mm}$ Tris$\mathrm{HCl}$, pH 7.5 containing $1 \mathrm{~mm}$ NEM, $1 \mathrm{~mm}$ EDTA, $10 \mathrm{~mm}$ AHA, $0.5 \mathrm{~mm}$ PMSF and $0.1 \%$ CHAPS. Aliquots of the dialyzed fractions were assayed for radioactivity. Each of the remaining dialyzed fractions was applied to a DEAE-Sephacel column $(1.0 \times 13 \mathrm{~cm})$ equilibrated with $7 \mathrm{M}$ urea $/ 0.1 \%$ CHAPS in $50 \mathrm{~mm}$ Tris-HCl, $\mathrm{pH} 7.5$. The column was washed with 75 $\mathrm{ml}$ of the same $7 \mathrm{M}$ urea solution, and the proteins bound to the column were eluted with a linear gradient of $0-1.0 \mathrm{M}$ $\mathrm{NaCl}(150 \mathrm{ml})$ and then with $2.0 \mathrm{M} \mathrm{NaCl}(30 \mathrm{ml})$ in the $7 \mathrm{M}$ urea solution. The flow rate was $0.5 \mathrm{ml} / \mathrm{min}$ and fractions of $3.0 \mathrm{ml}$ were collected. Aliquots of fractions were assayed for both activities of ${ }^{35} \mathrm{~S}$ and ${ }^{3} \mathrm{H}$ using a liquid scintillation counter. Fractions with both ${ }^{35} \mathrm{~S}$ and ${ }^{3} \mathrm{H}$ activities were divided and pooled into three parts: pass-through fraction
(Fraction 1), fraction eluted with $0.1-0.33 \mathrm{M} \mathrm{NaCl}$ (Fraction 2), and fraction eluted with $0.33-0.9 \mathrm{M} \mathrm{NaCl}$ (Fraction 3). In this way, Fractions OM1, OM2, and OM3 were obtained from medium of organ culture (OM); Fractions OE1, OE2, and $\mathrm{OE} 3$, from stromal extract of organ culture (OE); Fractions $\mathrm{CM} 1, \mathrm{CM} 2$, and $\mathrm{CM} 3$, from medium of cell culture (CM); and Fractions CE1, CE2, and CE3, from cell extract of cell culture (CE). Each fraction was dialyzed against $10 \mathrm{~mm}$ Tris- $\mathrm{HCl}, \mathrm{pH} 7.4$ containing $150 \mathrm{~mm} \mathrm{NaCl}$ and $0.2 \%$ Tween 20 and concentrated by ultrafiltration using YM 10 membrane. An aliquot of each concentrate was assayed for ${ }^{35} \mathrm{~S}$ and ${ }^{3} \mathrm{H}$ activities.

Enzymatic Treatment and Superose 6 Chromatography A portion of each concentrated fraction was digested with chondroitinase $\mathrm{ABC}$, keratanase, or endo- $\beta$-galactosidase at $37^{\circ} \mathrm{C}$ in $50 \mathrm{~mm}$ Tris- $\mathrm{HCl}$, pH 7.5, containing $40 \mathrm{~mm}$ NEM, 40 mм EDTA, $0.1 \mathrm{~mm}$ phenylmethylsulfonyl fluoride (PMSF), $1.4 \mathrm{~mm}$ pepstatin A to examine the glycosaminoglycan compositions of proteoglycans synthesized. Each fraction was digested with 0.25 unit ( $\mu \mathrm{mol}$ of unsaturated disaccharide $/ \mathrm{min}$ ) of chondroitinase $\mathrm{ABC}$ for $2 \mathrm{~h}$. Fractions OM3, OE3, CM3, and CE3 were digested for $4 \mathrm{~h}$ with 0.5 unit ( $\mu$ mol of reducing end $/ \mathrm{h}$ ) of keratanase, which cleaves internal galactosidic linkages but requires $\mathrm{N}$-actylglucosamine 6-O-sulfate residue adjacent to the galactose residue participating in galactosidic linkage; and the other fractions were digested for $4 \mathrm{~h}$ with 0.01 unit ( $\mu$ mole of reducing end $/ \mathrm{min}$ ) of endo- $\beta$-galactosidae, which cleaves not only KS but also undersulfated KS and nonsulfated KS (poly- $N$-acetyllactosamine). ${ }^{26)}$ The digests were applied to a Superose 6 column $(1.0 \times 30 \mathrm{~cm})$ equilibrated with $20 \mathrm{~mm}$ Tris- $\mathrm{HCl}, \mathrm{pH} 8.0$ containing $7 \mathrm{M}$ urea and $10 \mathrm{~mm} \mathrm{NaCl}$. The elution was performed with the same buffered $7 \mathrm{M}$ urea solution at a flow rate of $0.4 \mathrm{ml} / \mathrm{min}$, and fractions of $0.4 \mathrm{ml}$ were collected. A portion of each fraction was assayed for ${ }^{35} \mathrm{~S}$ activity using a liquid scintillation counter. The increases in ${ }^{35} \mathrm{~S}$ activity after fraction number 50, compared with the chromatography of corresponding intact PG fraction, were taken to represent products of degradation by the enzymes, and the glycosaminoglycan composition was calculated from their percent of total ${ }^{35} \mathrm{~S}$ activity eluted.

Immunoprecipitation Immunoprecipitation of KSPG or CSPG from each fraction was performed using antibody against KSPG core protein or CSPG core protein. The polyclonal antibodies against KSPG core protein (anti-KSPG) and CSPG core protein (anti-CSPG) were prepared as described previously. ${ }^{27)}$ Immunoprecipitation of KSPG and CSPG were done according to Funderburgh et al. ${ }^{21)}$ ProteinA-Sepharose CL-4B was washed with Mili-Q water and 10 $\mathrm{mm}$ Tris- $\mathrm{HCl}$, $\mathrm{pH} 8.0 / 150 \mathrm{~mm} \mathrm{NaCl} / 0.2 \%$ Tween 20 (hereafter referred to as $10 \mathrm{~mm}$ Tris-HCl-Tween. ${ }^{20)}$ The washed protein-A-Sepharose $(200 \mu \mathrm{l})$ was incubated with $100 \mu \mathrm{l}$ of the purified anti-KSPG or anti-CSPG and $200 \mu 1$ of $10 \mathrm{~mm}$ Tris-HCl-Tween 20 at $4{ }^{\circ} \mathrm{C}$ overnight on a rotating mixer, then washed once with $1 \mathrm{ml}$ of $10 \mathrm{~mm}$ Tris-HCl-Tween 20 . The antibody-loaded beads were then shaken with $1 \mathrm{ml}$ of 10 mm Tris-HCl-Tween 20 containing $1 \%$ of bovine serum albumin (BSA) for $2 \mathrm{~h}$ at $4{ }^{\circ} \mathrm{C}$, then washed three times with 1 $\mathrm{ml}$ of $10 \mathrm{~mm}$ Tris-HCl-Tween 20. Thereafter, $1 \mathrm{ml}$ of each sample (the OM, OE, CM, and CE fractions) was incubated with $200 \mu \mathrm{l}$ of the BSA-treated, antibody-loaded beads and 
$200 \mu \mathrm{l}$ of $10 \mathrm{~mm}$ Tris- $\mathrm{HCl}-$ Tween 20 at $4{ }^{\circ} \mathrm{C}$ overnight on a rotating mixer, then centrifuged $(1000 \mathrm{rpm}, 20 \mathrm{~s})$. The resultant pellet was washed with $1 \mathrm{ml}$ of $10 \mathrm{~mm}$ Tris-HCl-Tween 20 five times. The resultant supernatant was incubated again with $200 \mu \mathrm{l}$ of fresh antibody-loaded beads treated with BSA and centrifuged as described above. The washed 1st and 2nd pellets were separately incubated with $500 \mu \mathrm{l}$ of $20 \mathrm{~mm}$ Tris- $\mathrm{HCl}, \mathrm{pH} 8.0$ containing $7 \mathrm{M}$ urea and $0.1 \mathrm{M} \mathrm{NaCl}$ at $4{ }^{\circ} \mathrm{C}$ overnight on a rotating mixer to release the bound proteins from the beads, then centrifuged ( $15000 \mathrm{rpm}, 3 \mathrm{~min}$ ), and the two resultant supernatants were combined. A portion of the combined supernatant was assayed for ${ }^{3} \mathrm{H}$ and ${ }^{35} \mathrm{~S}$ activities using a liquid scintillation counter. The remaining supernatant was applied to a Superose 6 column $(1.0 \times 30 \mathrm{~cm})$ and chromatographed as described above. Fractions of $0.4 \mathrm{ml}$ were collected, and each fraction was assayed for ${ }^{3} \mathrm{H}$ and ${ }^{35} \mathrm{~S}$ activities.

\section{RESULTS}

Incorporations of $\left[{ }^{3} \mathrm{H}\right]$ Leucine and $\left[{ }^{35} \mathrm{~S}\right]$ Sulfate into Macromolecules Synthesized by Organ and Cell Cultures, and Distribution of the Incorporated Activities in Fractions 1, 2, and 3 after DEAE-Sephacel Chromatography As described under Materials and Methods, organ culture of stromal explants and cell culture of stromal cells were radiolabelled with $\left[{ }^{3} \mathrm{H}\right]$ leucine for core proteins and with $\left[{ }^{35} \mathrm{~S}\right]$ sulfate for glycosaminoglycan chains. Organ extract (OE), cell extract (CE), and media (OM, CM) obtained were chromatographed on a DEAE-Sephacel column and separated into three fractions: Fraction 1, pass-through fractions, containing nonsulfated PGs, hardly sulfated PGs and glycoproteins with some oligosaccharides; Fraction 2, fractions eluted with $0.1-0.33 \mathrm{M} \mathrm{NaCl}$, containing undersulfated PGs; Fraction 3, fractions eluted with $0.33-0.9 \mathrm{M} \mathrm{NaCl}$, containing highly sulfated PGs (binding of PGs to DEAE-Sephacel column is dependent only on negative charges per disaccharide repeat, because the core protein moiety of PG is not involved in the binding $\left.{ }^{27}\right)$. Table 1 shows incorporations of $\left[{ }^{3} \mathrm{H}\right]-$ leucine and $\left[{ }^{35} \mathrm{~S}\right]$ sulfate into macromolecules in extracts (of stromas and cells) and media, and distributions of the incorporated activities into Fraction 1, 2, and 3. In the organ culture, much higher activities of both ${ }^{3} \mathrm{H}$ and ${ }^{35} \mathrm{~S}$ were incorporated into organ extract than into medium. The major portions of ${ }^{35} \mathrm{~S}$ activities in both organ extract and medium fractions were recovered in Fraction 3 (OM3 and $\mathrm{OE} 3)$ after DEAE-Sephacel chromatography, while the ${ }^{3} \mathrm{H}$ activities in both organ extract and medium fractions were recovered in similar proportions in Fraction 2 (OM2 and OE2) and 3 (OM3 and OE3). In the cell culture, both ${ }^{3} \mathrm{H}$ and ${ }^{35} \mathrm{~S}$ activities incorporated into medium were comparable to those incorporated into cell extract. Like organ culture, the major portions of ${ }^{35} \mathrm{~S}$ activities in both cell extract and medium fractions were recovered in Fraction 3 (CM3 and CE3) after DEAE-Sephacel chromatography, but ${ }^{35} \mathrm{~S}$ activities were also recovered in Fraction 2 (CM2 and CE2) in proportions that were more than double those in Fraction 2 of organ culture (OM2 and OE2). On the other hand, ${ }^{3} \mathrm{H}$ activity in the medium fraction of cell culture was recovered in Fraction 2 (CM2) in a proportion comparable to that in Fraction 3 (CM3), and the major portion of ${ }^{3} \mathrm{H}$ activity in the cell ex-
Table 1. Incorporations of $\left[{ }^{3} \mathrm{H}\right]$ Leucine and $\left[{ }^{35} \mathrm{~S}\right]$ Sulfate into Macromolecules Synthesized in Organ and Cell Cultures, and Distributions of Incorporated Activities into Fractions 1, 2, and 3 Chromatographed on a DEAESephacel Column

\begin{tabular}{|c|c|c|c|c|c|}
\hline \multirow{2}{*}{ Culture } & \multirow{2}{*}{ Fraction } & \multicolumn{4}{|c|}{ Total activity (dpm) } \\
\hline & & ${ }^{35} \mathrm{~S}$ & & ${ }^{3} \mathrm{H}$ & \\
\hline \multirow[t]{8}{*}{ Organ culture } & Medium & 2674608 & & 661740 & \\
\hline & OM1 & 55674 & (2.6) & 69336 & (12.5) \\
\hline & OM2 & 112528 & (5.1) & 212160 & (38.3) \\
\hline & OM3 & 2029482 & (92.3) & 272484 & $(49.2)$ \\
\hline & Organ extract & 20761836 & & 9750390 & \\
\hline & OE1 & 72900 & $(0.7)$ & 581370 & $(9.8)$ \\
\hline & OE2 & 658470 & $(6.0)$ & 2498130 & (41.7) \\
\hline & OE3 & 10259920 & (93.3) & 2905300 & (48.5) \\
\hline \multirow[t]{8}{*}{ Cell culture } & Medium & 45211000 & & 12251000 & \\
\hline & CM1 & 157608 & $(0.7)$ & 845460 & (8.4) \\
\hline & $\mathrm{CM} 2$ & 3323376 & $(12.8)$ & 3557792 & (35.5) \\
\hline & $\mathrm{CM} 3$ & 22345740 & $(86.5)$ & 5627070 & $(56.1)$ \\
\hline & Cell extract & 12350000 & & 23309000 & \\
\hline & CE1 & 17332 & $(0.3)$ & 944076 & $(5.2)$ \\
\hline & CE2 & 1356300 & (14.6) & 15121860 & (83.3) \\
\hline & CE3 & 7880402 & (85.1) & 2086463 & (11.5) \\
\hline
\end{tabular}

The values in parentheses indicate the percent of the sum of activities in Fractions 1, 2 , and 3. The table is a composite of two separate experiments; standard errors are $<10 \%$ of the means.

tract fraction was recovered in Fraction 2 (CE2).

Comparable portions of ${ }^{35} \mathrm{~S}$ and ${ }^{3} \mathrm{H}$ activities which were originally found in organ extract, cell extract, and media, were lost after their DEAE-Sephacel chromatographies (Table 1). The reason for this is unknown: the extracts and media might still contain free ${ }^{35} \mathrm{~S}$ and ${ }^{3} \mathrm{H}$ precursors after dialysis and the precursors might still be retained on the column even after the elution with $2 \mathrm{M} \mathrm{NaCl}$.

Glycosaminoglycan Composition of PGs in Each Fraction Each fraction was digested with chondroitinase $\mathrm{ABC}$, keratanase, or endo- $\beta$-galactosidase, and the glycosaminoglycan composition of PGs therein was estimated from ${ }^{35} \mathrm{~S}$ activity as described under Materials and Methods. The results are shown in Table 2. In organ culture, the proportions of KS were much higher than those of CS/DS in both Fractions 2 and 3 (OM2 and OE2; OM3 and OE3), while the proportions of CS/DS were higher than those of KS in Fraction 1 (OM1 and OE1), although the ${ }^{35} \mathrm{~S}$ activities recovered in Fractions 1 was very low. On the other hand, the proportions of KS decreased markedly in Fractions CM3 and CE3 of cell culture compared to those in the corresponding fractions of organ culture, while those in Fractions CM2 and CE2 remained high. Consequently, the proportions of CS/DS PG in Fractions CM3 and CE3 increased. These results show that, in cell culture, the highly sulfated KS decreased markedly, while the undersulfated KS and highly sulfated CS/DS did not decrease. The amount of undersulfated KS in cell culture substantially increased compared to that in organ culture, as judged by the proportions (the values in parentheses) of ${ }^{35} \mathrm{~S}$ activities in Fraction 2 (OM2 to CM2; OE2 to CE2) in Table 
Table 2. Glycosaminoglycan Compositions of Proteoglycans in Each Fraction of Organ and Cell Culture

\begin{tabular}{|c|c|c|c|}
\hline \multirow{2}{*}{ Culture } & \multirow{2}{*}{ Fraction } & \multicolumn{2}{|c|}{ Percent of total ${ }^{35} \mathrm{~S}$ activities in each fraction } \\
\hline & & $\mathrm{KS}^{a)}$ & $\left.\mathrm{CS} / \mathrm{DS}^{a}\right)$ \\
\hline \multirow[t]{6}{*}{ Organ culture } & OM1 & 14.1 & 53.8 \\
\hline & OM2 & 60.0 & 37.1 \\
\hline & OM3 & 71.0 & 28.0 \\
\hline & OE1 & 29.9 & 47.7 \\
\hline & OE2 & 71.9 & 14.4 \\
\hline & $\mathrm{OE} 3$ & 63.2 & 36.8 \\
\hline \multirow[t]{6}{*}{ Cell culture } & CM1 & $-^{b)}$ & 40.9 \\
\hline & CM2 & 71.5 & 27.1 \\
\hline & CM3 & 18.0 & 80.2 \\
\hline & CE1 & $\underline{b}^{b}$ & b) \\
\hline & CE2 & 47.0 & 13.4 \\
\hline & CE3 & 17.5 & 51.2 \\
\hline
\end{tabular}

a) KS, keratan sulfate; CS/DS, chondroitin sulfate/dermatan sulfate. b) Not detected. The table is a composite of three separate experiments: Standard errors are $<5 \%$ of the means.

Table 3. Immunoprecipitations of Proteoglycans from Each Fraction of Organ and Cell Cultures Using Anti-KSPG and Anti-CSPG Core Proteins

\begin{tabular}{lccc}
\hline \hline \multirow{2}{*}{$\begin{array}{l}\text { Culture } \\
\text { Fraction }\end{array}$} & \multicolumn{2}{c}{ Percent of total ${ }^{3} \mathrm{H}$ activities in each fraction } \\
\cline { 3 - 4 } & & $\begin{array}{c}\text { Immunoprecipitates } \\
\text { with anti-KSPG }\end{array}$ & $\begin{array}{c}\text { Immunoprecipitates } \\
\text { with anti-CSPG }\end{array}$ \\
\hline Organ culture & OM1 & 24.4 & 30.2 \\
& OM2 & 12.6 & 8.1 \\
& OM3 & 37.5 & 14.0 \\
& OE1 & 25.4 & 43.5 \\
OE2 & 37.9 & 26.8 \\
& OE3 & 19.4 & 14.5 \\
\hline \multirow{2}{*}{ Cell culture } & CM1 & 10.7 & 14.4 \\
& CM2 & 18.9 & 30.6 \\
CM3 & 12.4 & 10.0 \\
CE1 & 35.6 & 40.6 \\
CE2 & 42.5 & 25.1 \\
CE3 & 5.9 & \\
\hline
\end{tabular}

The table is a composite of three separate experiments; standard errors are $<5 \%$ of the means.

1 and the proportions of $\mathrm{KS}$ in Fraction 2 (OM2 to CM2; OE2 to CE2) in Table 2.

Immunoprecipitation of PGs from Each Fraction of Organ and Cell Cultures To estimate the core protein moieties of PGs in each fraction, PGs were immunoprecipitated using anti-KSPG and anti-CSPG as described under Materials and Methods. The results are shown in Table 3. In a separate experiment, each sample was preincubated with Protein-A-Sepharose CL-4B and centrifuged, and the resultant supernatants were then subjected to immunoprecipitation (including blocking with BSA) as described under Materials and Methods. Because the results were similar to those in Table 3, the nonspecific adhesion of proteins in each sample to Protein-A-Sepharose CL-4B probably did not take place during the immunoprecipitations. But, even if the immunoprecipitation was repeated twice for each sample as described under Materials and Methods, the sum of percents of ${ }^{3} \mathrm{H}$ activities of immunoprecipitates with anti-KSPG and antiCSPG in each fraction, especially OM2, OE3, CM1, and
CE3, was much lower than $100 \%$. Although anti-KSPG and anti-CSPG antibodies are polyclonal, the PGs might not be completely immunoprecipitated with these antibodies. The reason for this is unknown: the glycosaminoglycan chains linked to core proteins may interfere with the antigen-antibody reaction. But the distribution of PG core proteins in each fraction can be found from the results in Table 3. The proportion $(5.9 \%)$ of immunoprecipitate $\left({ }^{3} \mathrm{H}\right.$ activity) with anti-KSPG in Fraction CE3 markedly decreased compared to that $(19.4 \%)$ in Fraction OE3, while the proportion (25.1\%) of immunoprecipitate with anti-CSPG in Fraction CE3 increased compared to that (14.5\%) in Fraction OE3. The proportion $(12.4 \%)$ of immunoprecipitate with anti-KSPG in Fraction CM3 also markedly decreased compared to that (37.5\%) in Fraction OM3, although the proportion (10.0\%) with anti-CSPG in CM3 also decreased a little compared to that $(14.0 \%)$ in OM3. In contrast, the proportions of immunoprecipitates with anti-KSPG and anti-CSPG in Fractions CM2 and CE2 all were more than those in Fractions OM2 and OE2 and showed a tendency to increase. Because the major portion of ${ }^{3} \mathrm{H}$ activity incorporated into cell extract was recovered in Fraction CE2 (Table 1), the above result shows that the immunoprecipitates with both antibodies in Fraction CE2 were much higher in amount compared to those in Fraction OE2. These results reveal that the highly sulfated KSPG markedly decreased in cell culture, while the undersulfated KSPG and CS/DS PG, as well as the highly sulfated CS/DS PG tended to increase.

Superose 6 Chromatography of Immunoprecipitates from Each Fraction Each of the immunoprecipitates obtained above was chromatographed on a Superose 6 column as described under Materials and Methods. The profiles of the immunoprecipitates from organ extract (OE) and medium $(\mathrm{OM})$ of organ culture are shown in Figs. 1 and 2. Figure 1 (OE) shows that KSPG and CS/DS PG immunoprecipitated from Fraction OE3 were of larger molecular size than those from Fractions OE2 and OE1. This difference in molecular size could be derived from the higher sulfation and longer chain of glycosaminoglycans of PGs of OE3 compared to those of OE2 and OE1, although the length of glycosaminoglycan chains was not determined in this study. Because the molecular sizes of immunoprecipitates of OE1 were similar to those of OE2 which contained the undersulfated glycosaminoglycans, the immunoprecipitates of OE1 could be proteins with nonsulfated glycosaminoglycans, but not short sugar chains. In the experiment of glycosaminoglycandegradative enzyme digestions of PGs described above, core proteins of KSPG and CS/DS PG were eluted around fraction number 50 on the same Superose 6 column (data not shown), also suggesting that the immmunoprecipitates of OE1 eluted before fraction number 50 on the column (Fig. 1F) are proteins with nonsulfated glycosaminoglycans. Immunoprecipitates of OE1 contained small amounts of proteins of larger molecular size (Figs. 1E, F), and these proteins may have longer, nonsulfated glycosaminoglycan chains. In Fig. 2 (medium of organ culture), the profiles of immunoprecipitates of OM3, especially the immunoprecipitates with antiCSPG (Fig. 2B), show the presence of proteins of small molecular size. These proteins could have short, sulfated glycosaminoglycan chains. The molecular sizes of the immunoprecipitates of OM1 and OM2 (Figs. 2C-F) were similar to 

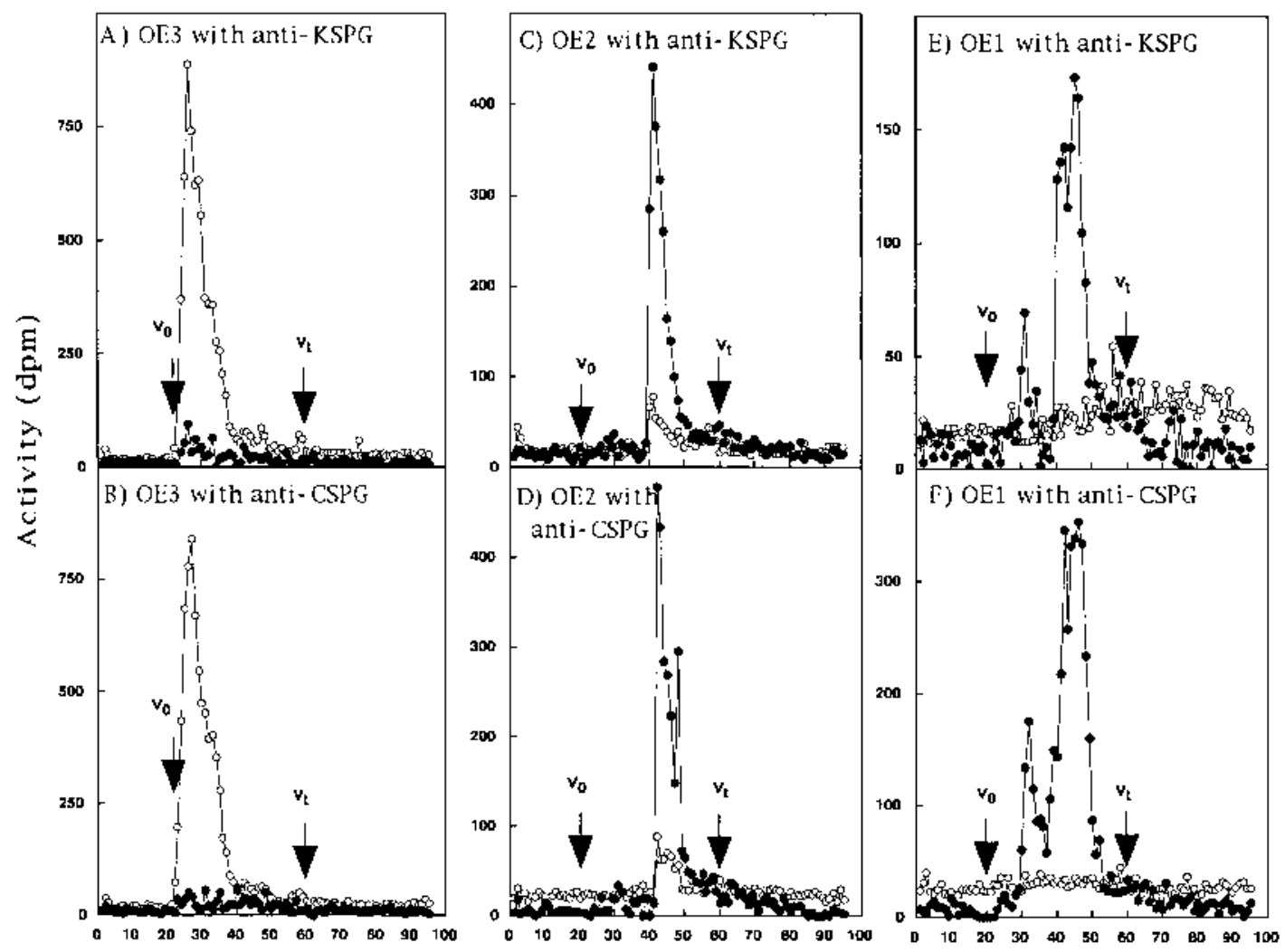

Fraction number

Fig. 1. Superose 6 Chromatography of the Immunoprecipitates from Fractions OE1, OE2, and OE3 (Organ Extract)

The immunoprecipitates with anti-KSPG and anti-CSPG from Fraction OE3 (A and B), Fraction OE2 (C and D), and Fraction OE1 (E and F) were each chromatographed on a Superose 6 column. The following symbols were used: open circles, ${ }^{35} \mathrm{~S}$ activity; closed circles, ${ }^{3} \mathrm{H}$ activity; Vo, void volume; Vt, total volume.

those of the smaller ones of OM3 as well as those of OE1 and OE2. The proteins of OM1 and OM2 could have nonsulfated and undersulfated glycosaminoglycan chains, respectively, like those of OE1 and OE2. The profiles of immunoprecipitates of cell culture (data not shown) were similar to those of the corresponding ones of organ culture (Figs. 1 and 2 ), except that the immunoprecipitates of CM1, not CE1, contained proteins of larger molecular size like those of OE1. These results of Superose 6 chromatographies show that PGs with undersulfated and nonsulfated glycosaminoglycan chains were synthesized and secreted into medium as final products in both cell culture and organ culture, and that PGs with short, sulfated glycosaminoglycan chains were also secreted into medium as final products in both cell culture and organ culture.

\section{DISCUSSION}

Many authors ${ }^{15-20)}$ have reported that when corneal stromal cells were cell-cultured, KS synthesis by the cells decreased markedly. In this study, the glycosaminoglycan compositions of PGs synthesized were examined by digesting them with keratanase, endo- $\beta$-galactosidase, and chondroitinase ABC (Table 2), and the core protein moieties were analyzed by immunoprecipitation with anti-KSPG and antiCSPG (Table 3). When the stromal cells were cell-cultured, the synthesis of highly sulfated KSPG markedly decreased, while that of highly sulfated CS/DS PG increased slightly. This result for the highly sulfated PGs is consistent with those reported previously. ${ }^{15-20)}$ We also found, however, that syntheses of both glycosaminoglycan backbone chain and core protein of the undersulfated KSPG, as well as the undersulfated CS/DS PG, increased in cell culture (the increase in $35 \mathrm{~S}$ activity in Fraction 2 means greater increase in glycosaminoglycan backbone, because the elution position of each Fraction on a DEAE-Sephacel column is dependent on the extent of sulfation per repeating disaccharide of the backbone). The proportions of the undersulfated KS (Fraction CE2) and CS/DS (Fractions CE2 and CM2) in cell culture were a little lower on the numerical values of ${ }^{35} \mathrm{~S}$ activity compared to the corresponding proportions in organ culture (Fractions OM2 and OE2) in Table 2. But it is clear that their percent of total ${ }^{35} \mathrm{~S}$ activities in the medium and extract fractions (the sum of Fractions 1, 2, and 3) of cell culture, respectively, were higher than those of organ culture because the proportions (12.8\% and $14.6 \%$ ) of ${ }^{35} \mathrm{~S}$ activities of Fractions CM2 and CE2 were more than twice those $(5.1 \%$ and $6.0 \%$ ) of Fractions OM2 and OE2 in Table 1. These results show that when the cells are cell-cultured, the sulfation of KS chains markedly decreases, whereas the syntheses of KS backbone and KSPG core protein are maintained at a higher level than that in organ culture; they also show that the sulfation of CS/DS chains and, the syntheses of CS/DS backbone and CS/DS PG core protein all increase compared to those in organ culture. We reported previously ${ }^{25}$ that GlcNAc-sulfotransferase activity markedly decreased compared to the other sulfotransferases and glycosyltransferases in cell culture. The result described above is consistent with this report. 


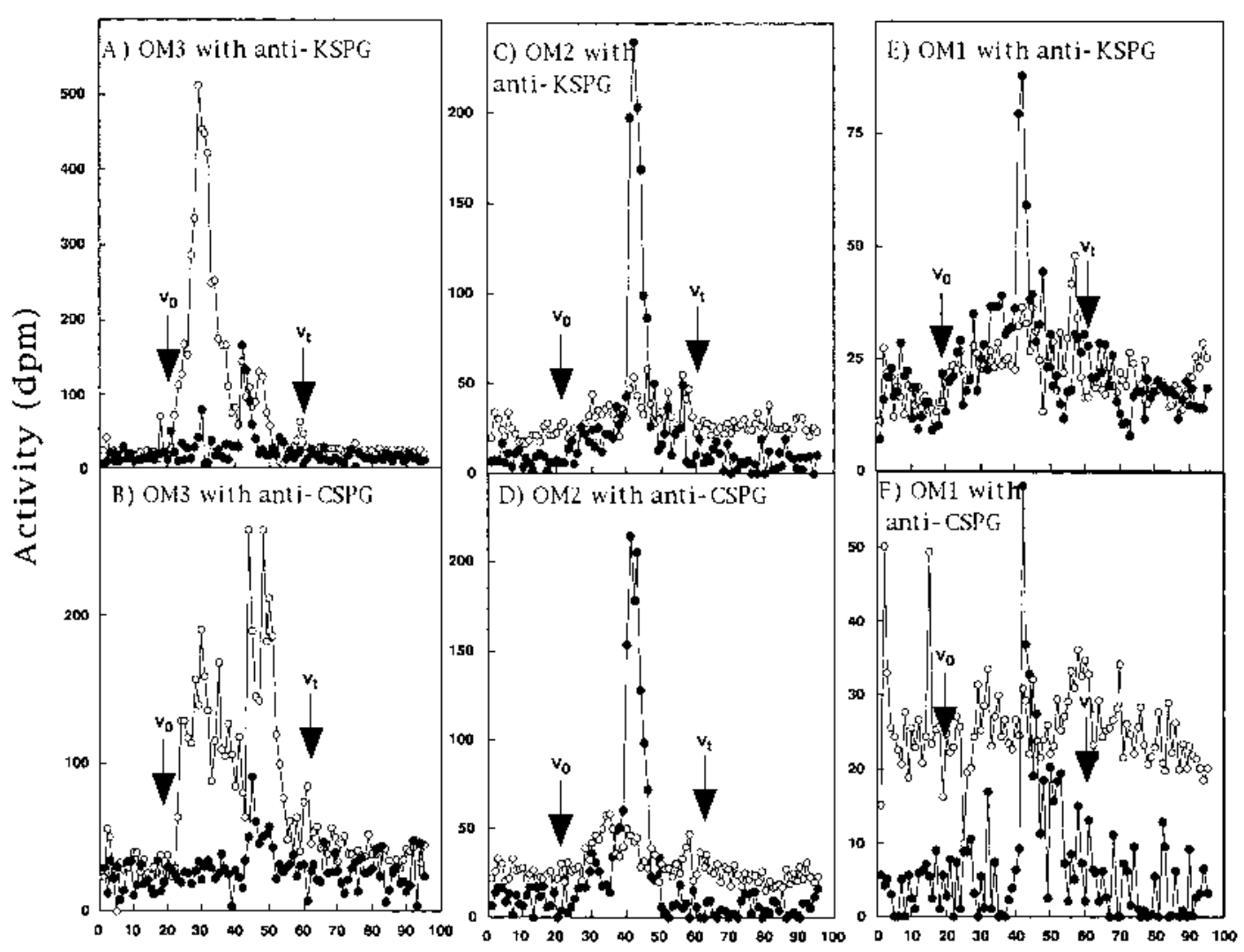

Fraction number

Fig. 2. Superose 6 Chromatography of the Immunoprecipitates from Fractions OM1, OM2, and OM3 (Medium)

The immunoprecipitates with anti-KSPG and anti-CSPG from Fraction OM3 (A and B), Fraction OM2 (C and D), and Fraction OM1 (E and F) were each chromatographed on a Superose 6 column. The symbols are as described in Fig. 1.

Superose 6 chromatographies of the immunoprecipitates (Figs. 1 and 2) show that PGs in Fraction 3 were of larger molecular size than those in Fractions 1 and 2. These differences in molecular size appear to derive primarily from the differences in the sulfation and length of glycosaminoglycan chains of PGs in each fraction. Although the length of glycosaminoglycan chains was not determined in this study, the undersulfated and nonsulfated glycosaminoglycan chains of PGs in Fractions 1 and 2 appear to be shorter than those in Fraction 3, because the differences between the elution positions on chromatographies are too great to be accounted for only by the extent of sulfation; furthermore, it has been reported that the sulfation of the glycosaminoglycan chain occurs during its polymerization ${ }^{28,29)}$ and that the glycosyltransferases involved in the chain elongation have higher activity toward the sulfated oligosaccharides than toward the nonsulfated ones ${ }^{30,31)}$ (the sulfation could be a rate-limiting step of the chain elongation). The results described above are consistent with those reported by Funderburgh $e t a .^{21)}$ and Schrecengost et $a .^{22)}$ The chromatographies in this study also show, however, that PGs with short, highly sulfated and long, nonsulfated glycosaminoglycan chains were present in both organ and cell cultures. The presence of these PGs in media of organ and cell cultures means that they were synthesized as final products and secreted into medium. The presence of PGs with short, highly sulfated and long, nonsulfated glycosaminoglycan chains in organ culture suggests that these PGs, as well as PGs with undersulfated glycosaminoglycan chains, are synthesized as final products and secreted into the extracellular matrix in vivo. What roles such PGs play in vivo and how the sulfation and elongation of glycosaminoglycan chain are controlled in vivo remain to be clarified.

Acknowledgments This work was supported by a Grantin-aid for Scientific Research No. 11671762 from the Ministry of Education, Science, Sports and Culture of Japan, by the Science Research Promotion Fund of the Promotion and the Mutual Aid Corp. for Private Schools of Japan, and by the Ministry of Education, Science, Sports and Culture of Japan (High-Tech Research Center Project).

\section{REFERENCES}

1) Li W., Vergnes J.-P., Cornuet P. K., Hassell J. R., Arch. Biochem. Biophys., 296, 190-197 (1992).

2) Blochberger T. C., Vergnes J.-P., Hempel J., Hassell J. R., J. Biol. Chem., 267, 347-352 (1992).

3) Corpuz L. M., Funderburgh J. L., Funderburgh M. L., Bottomley G. S., Prakash S., Conrad G. W., J. Biol. Chem., 271, 9759-9763 (1996).

4) Funderburgh J. L., Corpuz L. M., Roth M. R., Funderburgh M. L., Tasheva E. S., Conrad G. W., J. Biol. Chem., 272, 28089-28095 (1997).

5) Borcherding M., Blacik L. J., Sittig R. A., Bizzell J. W., Breen M., Weinstein H. G., Exp. Eye Res., 21, 59-70 (1975).

6) Hassell J. R., Cintron C., Kublin C., Newsome D. A., Arch. Biochem. Biophys., 222, 362-369 (1983)

7) Scott J. E., J. Biochem. Mol. Biol. \& Biophys., 2, 155-167 (1999)

8) Maurice D. M., "The Eye," 3rd ed., ed. by Davson, H., Vol. IB, Academic Press, London, 1984, pp. 1-158. 
9) Anseth A., Laurent T. C., Exp. Eye Res., 1, 25-38 (1961).

10) Axelsson I., Heinegård D., Biochem. J., 169, 517-530 (1978).

11) Hasssell J. R., Newsome D. A., Hascall V. C., J. Biol. Chem., 254, 12346-12354 (1979).

12) Axelsson I., Heinegård D., Exp. Eye Res., 31, 57-66 (1980).

13) Gregory J. D., Cöster L., Damle S. P., J. Biol. Chem., 257, 6965-6970 (1982).

14) Scott J. E., "Keratan Sulfate," ed. by Greiling H., Scott J.E., The Biochemical Society, London, 1989, pp. 122-134.

15) Yue B. Y. J. T., Baum J. L., Silbert J. E., Biochem. J., 158, 567-573 (1976).

16) Conrad G. W., Hamilton C., Haynes E., J. Biol. Chem., 252, 68616870 (1977)

17) Dahl I. M. S., Cöster L., Exp. Eye Res., 27, 175-190 (1978).

18) Dahl I. M. S., Exp. Eye Res., 32, 419-433 (1981).

19) Dahl I. M. S., Exp. Eye Res., 32, 435-443 (1981).

20) Nakazawa K., Morita A., Nakano H., Mano C., Tozawa N., J. Biochem. 120, 117-125 (1996).

21) Funderburgh J. L., Funderburgh M. L., Mann M. M. Prakash S., Conrad G. W., J. Biol. Chem. 271, 31431-31436 (1996).

22) Schrecengost P. K., Blochberger T. C., Hassell J. R., Arch. Biochem.
Biophys., 292, 54-61 (1992).

23) Beales M. P., Funderburgh J. L., Jester J. V., Hassell J. R., Invest. Ophthalmol. Vis. Sci., 40, 1658-1663 (1999).

24) Nakazawa K., Isomura T., Shimoeda S., J. Biochem., 117, 697-706 (1995).

25) Nakazawa K., Takahashi I., Yamamoto Y., Arch. Biochem. Biophys., 359, 269-282 (1998).

26) Nakazawa K., Ito M., Yamagata T., Suzuki S., Keratan Sulfate (Greiling H., Scott J. E., eds.), The Biochemical Society, London, 1989, pp. $99-110$.

27) Takahashi I., Nakamura Y., Hamada Y., Nakazawa K., J. Biochem., 126, $804-814$ (1999).

28) Sugumaran G., Silbert J. E., J. Biol. Chem., 265, $18284-18288$ (1990).

29) Moses J., Oldberg Å., Eklund E., Fransson L.-Å., Eur. J. Biochem., 248, 767-774 (1997).

30) Kitagawa H., Tsutsumi K., Ujikawa M., Goto F., Tamura J., Neumann K. W., Ogawa T., Sugahara K., Glycobiology, 7, 531—537 (1997).

31) Kitagawa H., Ujikawa M., Tsutsumi K., Tamura J., Neumann K. W., Ogawa T., Sugahara K., Glycobiology 7, 905-911 (1997). 